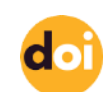

http://doi.org/10.22282/ojrs.2021.76

\title{
BLOOD PRESSURE IS THE KEY PHYSIOLOGICAL INDICATOR OF HIKING PERFORMANCE IN LASER SAILORS
}

\author{
Günay ERKAN*, Karasu ONUR*, Çetinkaya CANER*, Şahin TOLGA* \\ * Dokuz Eylül University, Faculty of Sport Science, İZMİR
}

\begin{abstract}
Purpose: This study aims to examine the physiological basis of hiking performance, which is the determinant of performance in laser class sailors.
\end{abstract}

ABSTRACT

Method: This research was conducted with 16 male athletes between the ages of 15-25 who actively attend laser class races held by the Turkish Sailing Federation. The participants were classified as High Performance (HP) and Low Performance (LP) according to their race results and the number of attended international races (as a member of the national team). Physical and anthropometric measurements, hiking performance measurements of these volunteers were obtained. During the hiking bench test, heart rate per minute, systolic and diastolic blood pressure values were monitored and recorded as well. One way ANOVA analysis of variance was applied to determine the differences of the resting levels of both study groups.

Result: Statistically significant differences were observed in the parameters of body mass index, systolic and diastolic blood pressure and heart rate during and after the test, and recovery heart rate in the HP and LP groups $(\mathrm{p}<0.05)$.

Conclusion: The findings of this study show that changes in the blood pressure parameters during Hiking performance are an important indicator of performance. Monitoring blood pressure in competition-based training can contribute to the determination of the sailor's performance level and training needs. It also shows that extensive researches with higher numbers of athletes are needed for future studies.

Key Words: Laser Sailing, Hiking test, Blood Pressure, Heart rate 


\section{INTRODUCTION}

Although sailing has a long history, it is striking that there are few scientific studies specific to sailing classes. Especially in an Olympic class such as laser, there are unclear areas in performance components. The basic features required by laser class sailors are defined as isometric strength, muscular endurance, cardiovascular endurance, balance, and coordination (1). While the duration in the laser class competition is over 30 minutes, it mainly benefits from aerobic energy metabolism, while sudden sail changes and changes in the wind conditions can increase the contribution of anaerobic metabolism $(1,2)$. In a study, aerobic energy participation of high-performing sailors and low-performing sailors in the 30-minute upwind state was measured and it was found that they gradually benefited from the aerobic energy path, while low-level sailors were found to use high energy expenditure and predominantly the anaerobic energy pathway $(3,4)$. This information is an indication that the economy of movement and the low energy consumption is directly related to the technique in sailing performance. When examining the studies on laser class aerobic capacity measurements, it was determined that elite laser sailors had $62 \mathrm{ml} / \mathrm{kg} / \mathrm{min}$. VO2max and national laser sailors 55 $\mathrm{ml} / \mathrm{kg} / \mathrm{min}$. (5). It is seen that laser class sailors have VO2max values up to $\mathrm{ml} / \mathrm{kg} / \mathrm{min}$.(6).

The hiking maneuver is required because the action of the wind on the sails causes the boat to heel, which increases its resistance and decreases its speed, making the use of hiking fundamental to correct the position of the boat to facilitate planning and, therefore, improving its speed and performance (7). An efficient hiking technique results in less friction between boat and water and therefore more speed (8). As the sailors finish \%94 of the Olympic races in which the wind speed varies between 5 and 15 knots, in the hiking position, they don't need the hiking position in lower wind speed (2). For laser classes, the time spent in the hiking position is closely associated with the performance.

The hiking position is the top physical challenge, for the laser class. It causes physical stress on the lower extremity (especially knee extensor muscle and hip flexor) and the upper extremity muscles due to the isometric contractions. Also, the rate of this physical load varies according to the wind intensity. The studies show that during the hiking position a sailor is exposed to \%10-20 of maximum voluntary contraction(MVC) in the downwind and to \%40-60 
of MVC in the upwind (9). In literature, the restrictive factors that affect hiking performances are knee extensor strength, weak technique and the lack of physical condition (10).

It is essential to increase the training on isometric muscle endurance and aerobic capacity usually on the land to improve performance (11). The hiking bench training, endurance, and the training of basic position technics are also implemented. In this study, physiological responses are the main focus which is provided by real-time feedback in the

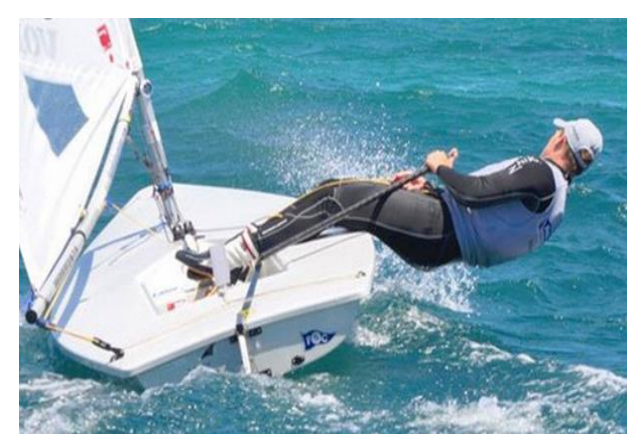
hiking position. This study aims to examine the physiological basis of hiking performance, which is the determinant of performance in laser class sailors.

Hiking position

\section{Method}

\section{Participants}

16 male laser class sailors participating in the races organized by the Turkish Sailing Federation were included in the study. Participants were divided into high performance (HP) and low performance (LP) groups according to competition result rankings and participation in international competitions (being a national athlete). All tests and measurements were conducted in the laboratory from August to October 2013 (year-round racing season). The values regarding the demographic and anthropometric characteristics of the participants are presented in Table 1.

Inclusion criteria in the research; It was determined as participating in the competitions held in the last season and continuing regular training. All subjects gave informed and written consent and the study was approved by the Dokuz Eylul University Non-Interventional Research Ethics Committee number 2014 / 24-32 dated 10/07/2014 and protocol number 1585GOA. 
Table 1. Demographic and Anthropometric descriptive values of Participants

\begin{tabular}{|c|c|c|c|c|c|c|c|}
\hline & & $N$ & Min. & Max. & Mean & $S d$ & P Values \\
\hline \multirow{2}{*}{ Age (year) } & H.P. & 8 & 16 & 19 & 17,1 & 1,2 & \multirow[b]{2}{*}{$P>0,05$} \\
\hline & L.P. & 8 & 15 & 22 & 17,5 & 3,0 & \\
\hline \multirow{2}{*}{$\begin{array}{c}\text { Training } \\
\text { experience(year) }\end{array}$} & H.P. & 8 & 5 & 9 & 7 & 1,3 & \multirow{2}{*}{$P<0,05^{*}$} \\
\hline & L.P. & 8 & 3 & 6 & 5 & 1,05 & \\
\hline \multirow{2}{*}{ Height (cm) } & H.P. & 8 & 162 & 176 & 170,7 & ,055 & \multirow[b]{2}{*}{$P>0,05$} \\
\hline & L.P. & 8 & 167 & 183 & 174,1 & 0,41 & \\
\hline \multirow{2}{*}{ Weight (kg) } & H.P. & 8 & 52 & 82 & 67,1 & 9,2 & \multirow[b]{2}{*}{$P>0,05$} \\
\hline & L.P. & 8 & 65,5 & 79 & 74,4 & 4,7 & \\
\hline \multirow[b]{2}{*}{$B M I(\mathrm{~kg} / \mathrm{m} 2)$} & H.P. & 8 & 19,8 & 27,4 & 22,9 & 2,3 & \multirow[b]{2}{*}{$P<0,05^{*}$} \\
\hline & L.P. & 8 & 23,5 & 25,7 & 24,5 & ,8 & \\
\hline
\end{tabular}

H.P: High performers, L.P: Low performers, BMI: Body mass index

\section{Procedure}

The tests were conducted for all participants at the same time of the day and under similar environmental conditions. The athletes were informed about full hydration conditions and not to use caffeine-containing liquids before the test. Measurements were carried out after the Hiking Simulator test trial. During the test, all participants were asked to show maximum performance in the tests.

\section{Anthropometric Measurements:}

Participant's heights were measured without shoes in a swimsuit. An electronic height meter and weighing system were used. It was measured automatically by determining the peak point while standing vertically with its feet adjacent on a flat surface with their back turned on the stadiometer (12,13). Body Mass Index was calculated in $\mathrm{kg} / \mathrm{m} 2$ (14).

\section{Minute Hiking Bench Test}

The hiking bench designed by the researcher was modeled by the size and angular values of the cockpit section of the boat used as a standard in laser class. The bench consists of 
a hiking strap and a gunwale. Participants warmed up for 10 minutes. The test started after 5 minutes of rest. On the bench, the participants were asked to keep their center of mass on the remotest point of the foot bar on a roller system which is built with resistance against their body weight. The participants were allowed to move during the position as long as they kept the $120^{\circ}-180^{\circ}$ angle between the body and the knee. They were motivated with encouraging expressions during the test and they were constantly informed about the time left. During the 5minute test, systolic and diastolic blood pressure (Omron M2 Basic USA) and heart rate figures (Polar RS 800 Finland) per minute were recorded. The measurements were reperformed not only soon after the test but also 90 seconds after the test.

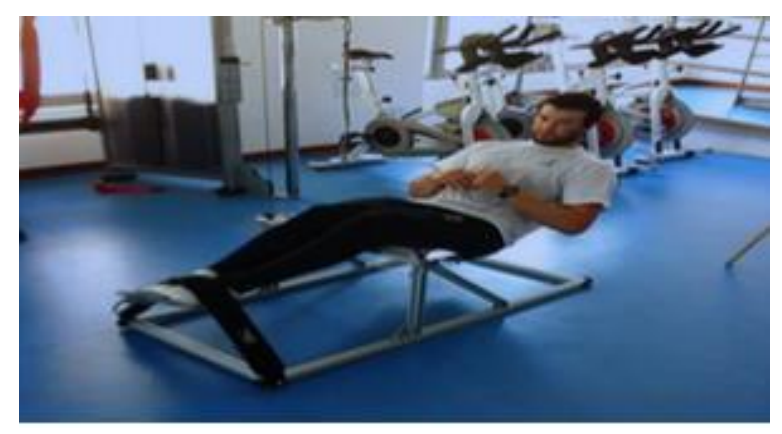

Hiking Bench Test.

\section{Statistical Analysis}

All of the statistical analysis were performed with Statistical Package Programme (Statistical Package for Social Science for Windows- SPSS, Version 22, NSA). Shapiro Wilk test was used to determine the distribution of data. One way ANOVA analysis of variance was applied to determine the differences of the resting levels of both study groups. (Repeated Measures ANOVA, analysis of variances was applied to evaluate the intergroup relations of the repeating measurements during the hiking performance. In statistical analysis, the level of significance was determined as less than $0.05(\mathrm{p}<0.05)$.

\section{Results}

The descriptive values of the participants are shown in table 1. The systolic blood pressure response of both groups during the hiking test was shown on graph 2 and the heart rate responses of both groups were shown in graph 3 . There were significant differences between 
the body mass index parameters of the participants $(\mathrm{p}<0,05)$. While the systolic heart pressure and heart rate values were significantly increasing at the beginning and the first 3 minutes of the test, there was a moderate increase in diastolic blood pressure.

Within the first 3 minutes of the test, as the systolic blood pressure, diastolic blood pressure and heart rate levels of the LP group increased, the heart rate parameter of the HP group increased statistically $(\mathrm{p}<0,05)$. The mean values of all responses after 3 minutes showed a higher increase in the LP group.

The LP group showed significantly higher heart rate response on the post-test recovery heart rate values $(\mathrm{p}<0,05)$.

Graphic 1. Systolic Blood Pressure response in both groups during hiking simulator test.

\section{SYSTOLIC RESPONSES}

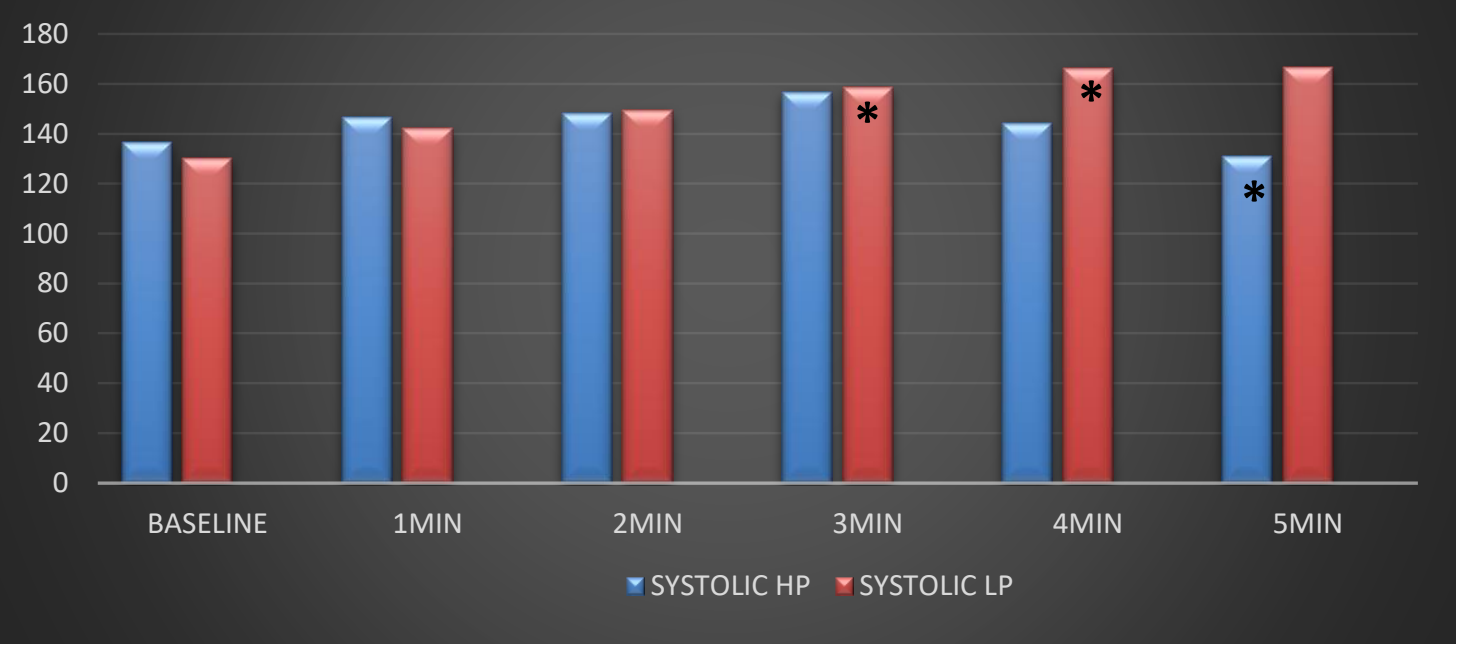




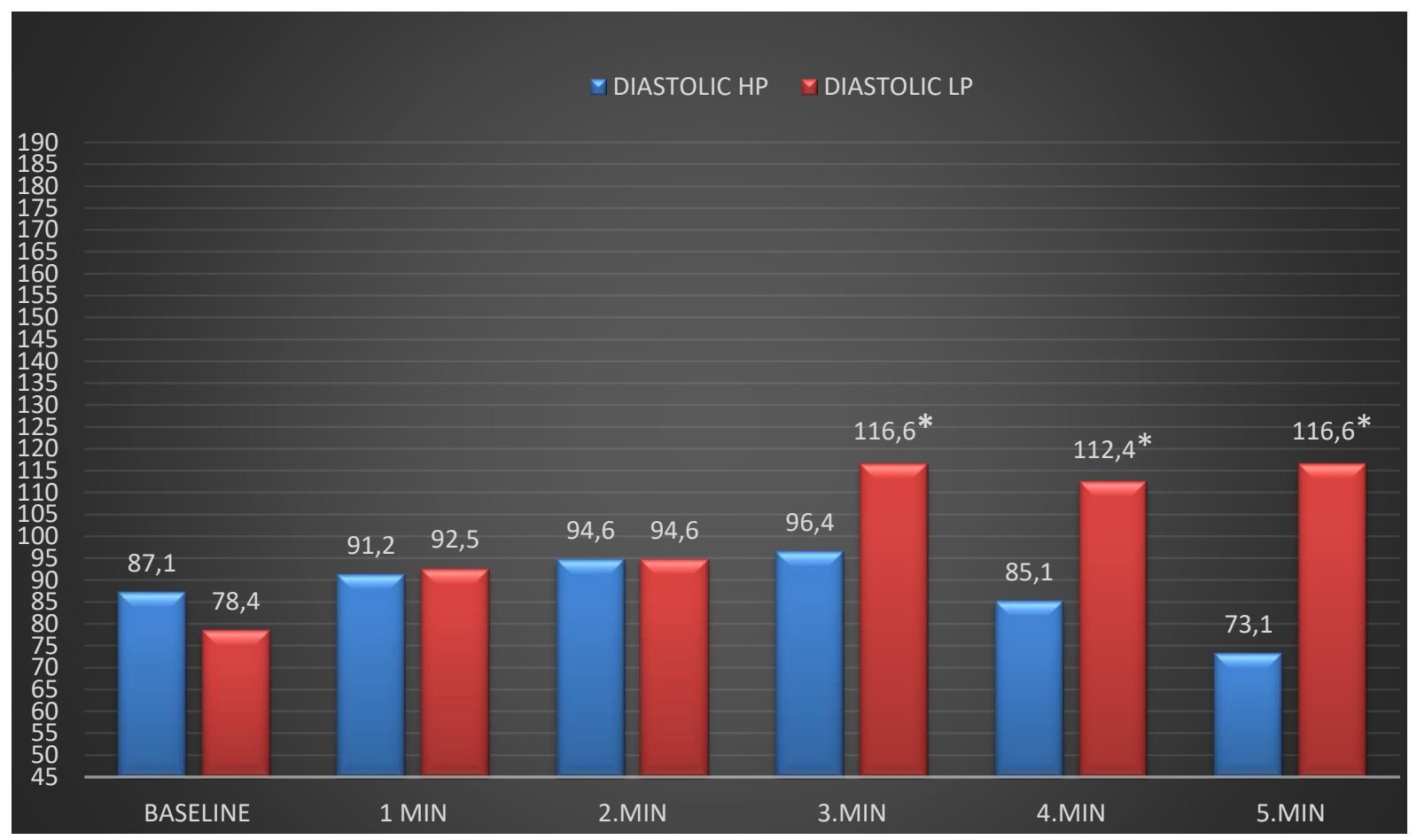

Graphic 3. Heart rate response in both groups during hiking simulator test.

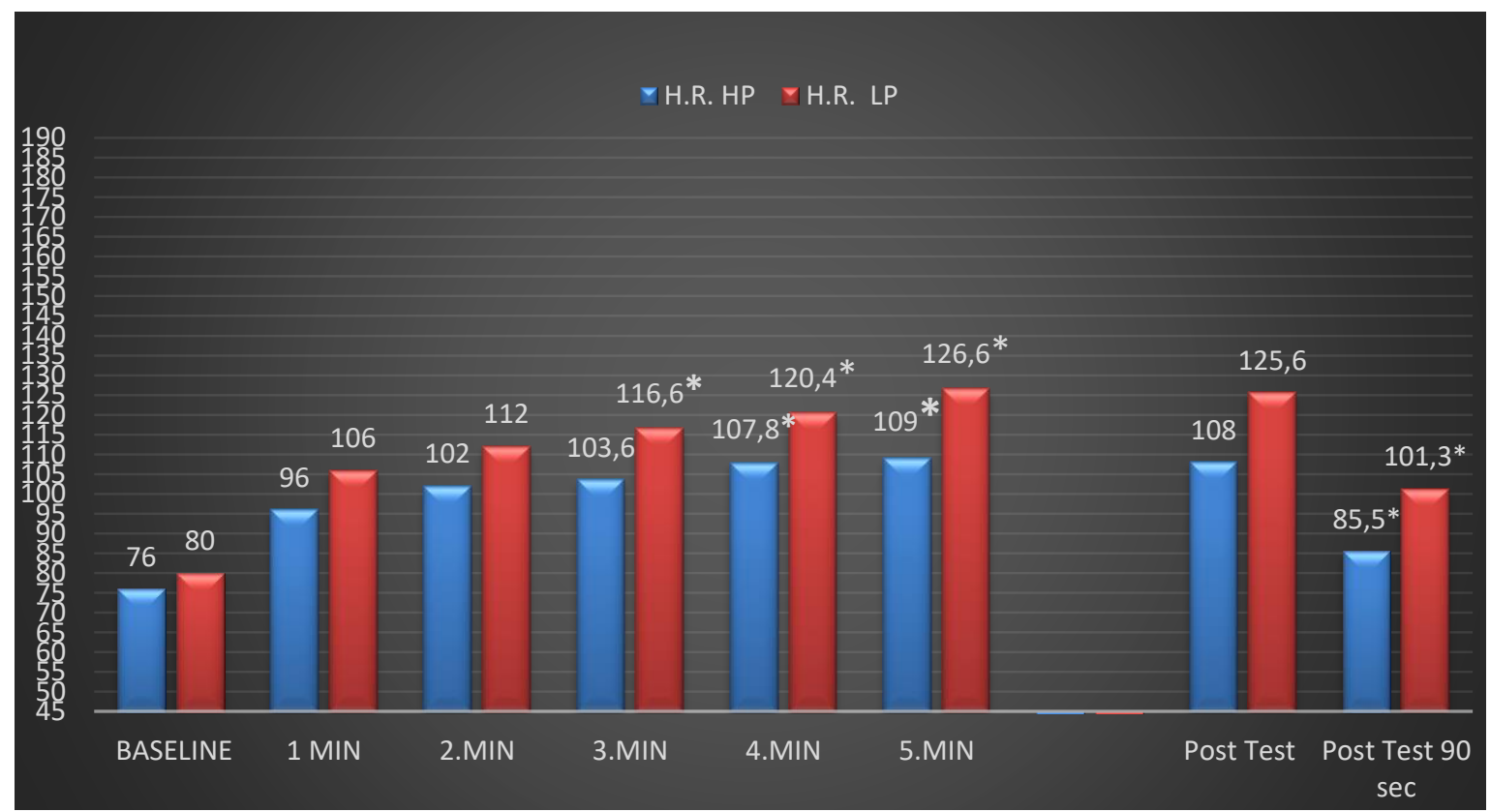




\section{Discussion}

The main finding of the research is to identify that blood pressure is a restrictive factor on hiking performance. Regarding the study result, it is found that the body mass index values of the HP group are significantly lower than the LP group For sailing, not only the ergonomy of the equipment used but also the physical condition of the sailor are important parameters that affect the performance. Studying the literature, Slater et al. research about the dietary habits and the physical features of dinghy class sailors show similarities with the HP group on BKI average values (15). In Another research, Burgois et al. show that the BKI parameters of sailors who perform highly in upwind conditions are significantly high (16). There are many nonphysiological processes in sailing performances. These are mainly cognitive qualities, the ability to comprehend the wind, and the ability of tactical perception. High body mass index on upwind conditions seems to influence the sailing speed positively. However, as keeping the hiking position for a long time influences the performance positively, more ergonomic body mass index parameters provide an advantage. Low body mass index can also positively affect the level of energy expenditure during the performance.

During the first minutes of the hiking test, an exponential rise was monitored in systolic blood pressure while the diastolic blood pressure increased moderately. But after the third minute, that the systolic and diastolic blood pressure figures kept rising is a crucial finding. The study of Blackborn et al. shows similar outcomes on average systolic and diastolic blood pressure values on hiking position (17). This suggests that the reduction in the amount of blood returning to the heart and the difficulty of oxygen delivery to active muscles, together with the compression of blood in the working muscles during isometric contraction, may be factors that provoke the increase in systolic and diastolic pressure. Meanwhile, it shows that the workload of the heart increases, and cardiac performance is impaired to re-establish a steady-state by stimulating the cardiovascular mechanisms via chemoreceptors.

Another important aspect is that the athletes being allowed to move during the test caused the dynamic contractions. Dynamic processes on the upper extremity in the field weakens the idea that hiking performance is a fully isometric contraction process. In the LP group, a range of motion during the hiking makes no difference considering the cardiovascular response; however, in the HP group, there is such a decrease. 
In the research, the heart rate of both groups appears similar in the first 3 minutes but after the third minute, the heart rate of the LP group significantly rises. It is also believed that the significant changes in the heart rate responses of the participants are a result that they were allowed to move and change the body-knee angles. Post-test recovery (90 seconds) heart rate responses show that the HP group tends to get close to baseline while the LP group significantly remains stable. The study of Vangelakouli et al. shows that there is no huge difference in simulator test heart rate between the elite and sub-elite sailors but post-test shows that sub-elite sailors have higher heart rate responses (18 In other research, Vaan delden et al. found similar heart rate responses under field conditions (19). The research finding which is highly collaborating with literature data shows that recovery heart rate is an important indicator of performance. This datas also underlines the aerobic endurance in the performance.

\section{Limitations}

It is a fact that there are more dynamic phases in real-time conditions. This study only focuses on isometric phases. The limitation of this study is that upper extremity strength parameters during the hiking test weren't evaluated.

\section{Conclusion}

The research findings show that instant monitorization of blood pressure parameters during the hiking position is critically important while evaluating the performance. It is also thought that the determination of blood pressure deviation points will provide information that can be used in training design. In future studies, the topic needs to be examined in depth in field conditions.

\section{REFERENCES}

1. Bojsen-Moller, $\mathbf{J}$ 'Yatch type and crew-specific differences in antropometric, aerobic capacity, and muscle strength parameters among international olympic class sailors', Journal of sports sciences, 2007

2. Tan, Benedict, vd. "Indicators of Maximal Trapez Performance in Laser Sailors". European Journal of Applied Physiology, September 2006;2: 169-76.

3. Vogiatzis I, Spurway N, Wilson J ' On water oxygen uptake measurements during dinghy sailing'. J Sports Sci 1994;12: 153. 
4. Vogiatzis I, Spurway NC, Jennett S, Wilson J, Sinclair J., 'Changes in ventilation related to changes in electromyograph activity during repetitive bouts of isometric exercise in simulated sailing'. Eur J Appl Physiol Occup Physiol 1996; 72:195-203.

5. Alpagut A., Soyer O. , Laser ve Ötesi, İstanbul, 2011.

6. Cunningham, Peter, ve Tudor Hale. "Physiological Responses of Elite Laser Sailors to 30 Minutes of Simulated Upwind Sailing”. Journal of Sports Sciences, 2007;10: 110916.

7. Chicoy-García, I., \& Encarnación-Martínez, A. (2015). Determining factors in the performance of hiking in dinghy sailing: A literature review. European Journal of Human Movement, 34, 15-33

8. Sprada, F., Schütz, G. R., Cerutti, P. R., Calado, L. Brito, H., \& Roes, H. (2007). Biomechanical analysis of spine movements in hiking on sailing. XXV ISBS Sym posium 2007,

9. Bojsen-Moller, J. 'Physical Requirements in Olympic Sailing' European Journal of Sport Science, April 2015;15: 220-27.

10. Callewaert M, Boone J, Celie B, De Clercq D, Bourgois JG. 'Indicators of sailing performance in youth dinghy sailing',Eur J Sport Sci. 2015;15(3):213-9.

11. Blackburn M (2000b). Sailing Wtness. In: Tan B (ed) The com-plete introduction to Laser racing. Singapore Sports Council, Singapore, pp 173-200.

12. Zorba E. 'Vücut Yapısı Ölçüm Yöntemleri ve şişmanlıkla Başa Çıkma', 1. Basım, Morpa Kültür Yayınları, istanbul 2005; 69-81, 105-131.

13. Kamar A. 'Sporda Yetenek Beceri ve Performans Testleri'. Ankara: Nobel Yayın Dağıtım; 2008.

14. Acsm's Health-related physical fitness assessment manual. Lippincott Williams\&Wilkins, 3 rd ed. Philadelphia, 2010.

15. Slater, Gary, ve Benedict Tan. "Body Mass Changes and Nutrient Intake of Dinghy Sailors While Racing". Journal of Sports Sciences, 10, August 2007;25: 1129-35.

16. Bourgois JG, Callewaert M, Celie B, De Clercq D, Boone 'Isometric quadriceps strength determines sailing performance and neuromuscular fatigue during an upwind sailing emulation', J Sports Sci,2016;34(10):973-9.

17. Blackburn M, 'Physiological responses to 90 min of simulated dinghy sailing', J Sports Sci 1994;12: 15390.

18. Vangelakoudi, A., Vogiatzis, I., \& Geladas, N. (2007). Anaerobic capacity, isometric endurance and Laser sailing performance. Journal of Sports Sciences, 25(10), 10951100.

19. Vaan Delden M, Bongers CCWG, Broekens D, Daanen HAM, Eijsvogels TMH, 'Thermoregulatory burden of elite sailing athletes during exercise in the heat: A pilot study,Temperature, 2018, 13;6(1):6676. 